\title{
Offshoring Tasks, yet Creating Jobs?
}

\author{
Wilhelm Kohler \\ Jens Wrona
}

CESIFO WORKING PAPER No. 3019

Category 8: Trade Policy

APRIL 2010
An electronic version of the paper may be downloaded
- from the SSRN website:
- from the RePEc website:
- from the CESifo website:
www.SSRN.com
Www.RePEc.org
www.CESifo-group.org/wp




\title{
Offshoring Tasks, yet Creating Jobs?
}

\begin{abstract}
We show that in a Ricardo-Viner-type trade model with unemployment due to search and matching the productivity effect of offshoring emphasized by Grossman \& Rossi-Hansberg (2008) emerges as a vehicle of job creation. Improvements in the technology of offshoring causes job losses at the extensive margin where ever more tasks are performed abroad, but it also causes job creation from cost-savings associated with enhanced trade in tasks. We identify conditions under which job creation dominates job destruction. We also show that employment may follow a non-monotonic pattern of adjustment to successive improvements in the technology of offshoring.
\end{abstract}

JEL-Code: F16.

Keywords: offshoring, trade in tasks, unemployment, search and matching.

\author{
Wilhelm Kohler \\ Eberhard Karls University Tübingen \\ Nauklerstrasse 47 \\ 72074 Tübingen \\ Germany \\ wilhelm.kohler@uni-tuebingen.de
}

\author{
Jens Wrona \\ Eberhard Karls University Tübingen \\ Mohlstrasse 36 \\ 72074 Tübingen \\ Germany \\ jens.wrona@uni-tuebingen.de
}

April 12, 2010

We thank the participants of the Brown Bag Seminar at Tübingen University as well as the seminar participants of the THE X-mas Workshop at Hohenheim University, and the 12th International Economic Relations Workshop at Göttingen University. We thank especially Udo Kreickemeier and Hartmut Egger for helpful comments and discussion. We have also benefited from a stimulating discussion by Hans-Jörg Schmerer at the THE X-mas Workshop. 


\section{Introduction}

Economic globalization has reached unprecedented "levels of resolution". Due to advances in the technology of communication and transport, international division of labor affects ever finer slices of the value added chain. Grossman \& Rossi-Hansberg (2008) speak of a new paradigm that they call trade in tasks. Arguably, staunch believers in gains from trade should welcome this development. If trade is good, then more of it - through trade in tasks - is better. If certain domestic jobs are lost, it is because their opportunity cost exceeds the cost of offshoring. Keeping such jobs would be tantamount to forgone efficiency gains.

This view stands in marked contrast with the widespread anxiety that "high-resolution globalization" meets in the general public and with many policy makers. Typically, offshoring comes with an unbundling of production processes, whereby certain workers face competition head on from foreign labor on the level of single tasks within their firms, as opposed to competition on the level of finished goods which mainly takes place between firms, thus affecting different types of workers on a more equal footing. Offshoring reflects what might be called a new industrial revolution, based on technological as well as social change, that undermines the traditional firm as an "organic solidarity among its members". ${ }^{1}$ It is certainly among the most ostensible hallmarks of this change. As a result, many workers now perceive a much more precarious job environment than they did 20 years ago. It is widely taken for granted that in the near future enhanced task-level arbitrage across high- and low-wage countries will be responsible for job losses or wage cuts for certain parts of industrial countries' labor force. Indeed, in the aggregate it may even increase both, the degree of inequality and the level of unemployment, although the quantitative importance of this adjustment is subject to debate.

Are higher wage inequality or unemployment inevitable consequences of "high-resolution globalization"? On an empirical level, the contribution of offshoring to wage inequality and unemployment is very difficult to establish. Some authors point out that wage cuts and job losses due to offshoring are minuscule, relative to the overall labor market turnover; see Bhagwati, Panagariya \& Srinivasan (2004). Others point out that the big wave of offshoring is yet to come. ${ }^{2}$ Thus, Blinder $(2006,2009)$ argues that offshoring in industrial countries like the US is likely to become a much "bigger deal" than many sanguine observers appear to expect, with fundamental consequences for domestic labor markets. He anticipates a significant increase in the scope and magnitude of offshoring from vast future improvements in all sorts of

\footnotetext{
${ }^{1}$ See Cohen (2009) for a description of this loss of solidarity which was at the heart of the 20th century industrial firm.

${ }^{2}$ See OECD (2007) as well as Bottini, Ernst and Luebker (2007) for a concise survey of empirical studies.
} 
technologies that are relevant for linking different types of tasks involved in manufacturing as well as services. He sees significant potentials for both job, creation and job destruction, but expects a sizable net job destruction for the US.

On a more general level, other things equal, more open economies do not consistently appear to face more unemployment; see Felbermayr, Pratt \& Schmerer (2009). At the same time, however, we do have solid micro-level evidence that offshoring has caused job losses in some countries and periods in time. ${ }^{3}$ If this does not show up in aggregate studies of globalization and unemployment, it may be for two reasons. The first is the notorious measurement problem: Offshoring is not a well defined statistical category recorded in trade and employment data. The second is somewhat more subtle. If globalization is mainly driven by lower costs of cross-border transactions, as often argued particularly in the context of offshoring, then economies that already do much of it would seem in a better position to reap benefits from getting even more. Formally, at the initial margin of autarchy, the very first step of globalization does not involve any first-order effect of cost-savings, while subsequent steps do. Therefore, the relationship between changes in offshoring and changes in unemployment may be non-monotonic. If so, then empirical studies that do not control for this type of non-monotonicity will fail to detect the true relationship between globalization and unemployment.

Currently, we do not have any simple theoretical model that would imply such a non-monotonic relationship. General equilibrium theory of trade would lead us to expect that if offshoring is driven by less costly trade in tasks, then there should be cost-savings which are reflected in the form of higher factor earnings or enhanced employment somewhere in the economy. ${ }^{4}$ It would seem odd, however, that such gains should accrue to the type of workers whose tasks have been moved offshore. Yet, this is precisely what happens in a model of task trade recently proposed by Grossman \& RossiHansberg (2008): Offshoring of tasks performed entirely by low-skilled labor entails a rise in the wage for domestic low-skilled workers. It does so, because the cost of low- and high-skilled labor are uniquely tied down in general equilibrium by zero-profit conditions, assuming that both types of labor are completely mobile across two industries that differ in the skill-intensity of production, and provided that both industries are and remain viable domestically. The point is that cheaper offshoring lowers the cost of tasks already performed abroad, thus reducing the cost of low-skilled labor as a whole. With unchanged final goods prices, this needs to be fully offset by a rise in the domestic low-skilled wage rate. Grossman \& Rossi-Hansberg (2008) call this the productivity effect of offshoring. Of course, a completely analogous

\footnotetext{
${ }^{3}$ See the NAPA (2006) report for the U.S. and the ERM (2007) report for the European Union.

${ }^{4}$ Of course, the same need not hold true if offshoring is an integral part of adjustment to some other exogenous shock, say a change in final goods prices.
} 
productivity effect obtains if offshoring takes place in tasks performed by high-skilled, instead of low-skilled labor.

But how does the economy absorb the loss in labor demand caused by offshoring? With all cost-savings fully absorbed by a rise in the low-skilled wage rate, the wage for high-skilled labor remains unchanged and firms face no incentive to change their input mix. At the same time, since a larger part of low-skilled labor tasks is now performed offshore, this implies lower demand for domestic low-skilled labor per unit of output in both industries. With perfect labor mobility across industries, a full employment equilibrium is restored through a reallocation of both types of labor towards the less skill-intensive of the two industries. This is perfectly analogous to the Rybczynski-type reallocation that takes place when an economy absorbs increased endowment of low-skilled labor. For this reason, Grossman \& RossiHansberg (2008) speak of a supply effect of offshoring. A similar effect may arise for high-skilled labor, again with reallocation of both types of labor restoring a full employment equilibrium.

However, ruling out any aggregate employment effect by assuming smooth Rybczynski-type reallocation seems questionable. In the short run, workers who lose some of their tasks to offshoring may be specific to the industry. The negative labor demand shock will then have to be absorbed within the industry. In such an environment, offshoring surely seems like a much more serious threat to workers, more in line with the anxiety that we observe in the policy debate. In the presence of labor market frictions, adjustment will most probably hold the specter of higher unemployment among the workers affected by offshoring of tasks.

In this paper, we place the Grossman \& Rossi-Hansberg (2008) paradigm of offshoring in a modeling setup that reflects these criticisms and, thus, is significantly less benign. In particular, we allow for unemployment effects due to search and matching frictions in the labor market. As in the real world, workers therefore not only face the specter of competition from foreign labor, but also the threat of unemployment. Reflecting our intention to move away from the benign environment of smooth reallocation, we go to the far extreme of assuming that workers are locked in a single sector that features offshoring and cannot move to employment in other sectors.

Technology involves different tasks that are more or less impersonal in the sense of Blinder (2009). A task which is completely impersonal need not be performed by workers in physical presence at the location of all other inputs, but may instead be performed abroad, with relatively little extra cost of linking the task with other tasks and other inputs into the firm's production. Tasks that are less impersonal in nature involve some extra cost. We model this notion of more or less impersonal tasks using an offshoring cost schedule for a continuum of tasks, as suggested by Grossman \& Rossi-Hansberg (2008). The margin between tasks performed domestically and abroad is determined 
by a foreign labor cost advantage. Blinder (2009) and others have emphasized that the exposure to offshoring of tasks has little to do with the skill-level of jobs. Our model reflects this by abstaining from the low- vs. high-skilled dichotomy of the labor force, assuming instead a single type of labor.

Contrary to a-priori intuition and wide-spread belief, it turns out that in such an economy enhanced offshoring of tasks need not destroy jobs. Indeed, offshoring may even generate additional domestic jobs. The reason is that with trade in tasks domestic employment involves a twin margin of adjustment. At the extensive margin, jobs are lost if cheaper offshoring prompts firms to enhance the set of tasks performed abroad. This is the Grossman \& Rossi-Hansberg (2008) supply (or endowment) effect. However, at the intensive margin, cheaper offshoring means lower labor cost as a whole, which prompts firms to expand employment for the entire set of tasks, including the ones for which domestic procurement is still cheaper. In labor markets characterized by search and matching, the Grossman \& Rossi-Hansberg (2008) productivity effect of offshoring emerges as a vehicle of potential net job-creation.

However, job-creation is not a foregone conclusion. It emerges only if the expansionary intensive margin effect is sufficiently strong. We derive sufficient conditions for a positive net job creation effect from an improvement of the technology of linking tasks across distance and borders. Two types of conditions are emerging. There is the "local condition" relating to the margin that separates domestic from offshore performance of tasks. And secondly, there is what we call the "interval property" of an equilibrium, which describes the position of this margin within the interval, as well as infra-marginal properties of the aforementioned offshoring cost schedule. This schedule captures the variation across the entire continuum of tasks in terms of being more or less impersonal. While we do not present any empirical analysis in this paper, it is important to note that our key proposition formulates these conditions in such a way that they are amenable to empirical observation.

As a result of the twin-margin-adjustment, the outcome may be a nonmonotonic relationship between movements at the extensive margin, where ever less impersonal tasks become subject to offshoring, and the employment level of domestic labor. Starting out with zero offshoring, successive improvements of the offshoring technology will first harm labor in terms of both, a wage cut and lower employment. In other words, for low levels of offshoring the extensive margin of job losses dominates the adjustment. But once the economy has reached a critical level of offshoring, the intensive margin of job creation may dominate the extensive margin, so that offshoring becomes a vehicle of net job creation. We present numerical simulations that substantiate our theoretical analysis and highlight some important implications. In particular, we identify a principal distinction between two types of industries, separated by a fundamental difference in their offshoring technologies. The 
distinction can loosely be described as one between "deep" and "shallow" comparative advantage. Our numerical analysis shows that these two types of industries will exhibit distinct patterns of employment effects as they engage ever deeper into offshoring in a scenario of the type foreseen by Blinder (2009).

Our paper is structured as follows. In the next section we develop a stylized model of offshoring and unemployment. Offshoring is modeled as trade in a continuum of tasks. Unemployment is determined by labor market frictions modeled along the familiar paradigm of search and matching. The trading equilibrium involves imports of tasks in exchange of exports of the final good. Section 3 presents a complete comparative static analysis, with a clear focus on domestic net job creation, whereby the exogenous shock is an improvement in the offshoring technology. In section 4, we derive two propositions on the employment effect of such a technology shock. The first highlights the role of labor market institutions, as opposed to the offshoring technology. The second proposition identifies sufficient conditions for a non-monotonic pattern of net job creation to emerge in a process of successive improvements of the offshoring technology. Section 5 turns to a numerical treatment, intended to develop a deeper understanding of the detailed properties of the offshoring technology that are responsible for such non-monotonicity.

\section{A Model of Offshoring and Unemployment}

\subsection{Production}

Our economy produces a single good $x$ which also serves as our numéraire. ${ }^{5}$ Production of good $x$ involves labor $l$ according to

$$
x=F(l):=A l^{\delta} \quad \text { where } \quad 0<\delta<1 .
$$

\footnotetext{
${ }^{5}$ As we have emphasized above, our deliberate intention is to move away from the benign environment of a smooth, Rybczynski-type reallocation of factors, which has counterfactual implications, as emphasized above. Feenstra (2010) shows that these implications may disappear also in a conventional $2 \times 2$ model, once we allow the economy to be large. Reallocation is then subject to goods price changes. In other words, it no longer is of a Rybczynski-type. However, in view of the argument, put forward by Bhagwati (2009), Lawrence (2009) and many others, that offshoring is a relatively minor phenomenon for the aggregate economy, terms of trade feedbacks would seem a somewhat questionable mechanism to rely on. Hence, we follow a different route to avoid the implausibly benign environment implicit in Grossman \& Rossi-Hansberg (2008) that features complete absence of all reallocation by assuming a single-sector economy. Feenstra (2010, p.40) briefly mentions this case. We present a detailed analysis, allowing for unemployment through search and matching frictions. An extended version of this paper featuring a two-sector model can be obtained upon request.
} 
Concavity of $x$ in $l$, for $\delta<1$, may be interpreted as the presence of a second factor, say capital, which is fixed in supply. It is straightforward to show that the profit-maximizing employment level $l$ must satisfy

$$
l=\delta x / W
$$

and maximum profits are equal to

$$
\pi=(1-\delta) x
$$

where $x$ is as given in (1), with input levels satisfying (2). Profits may be interpreted as income to owners of the second factor capital. Given wagecosts per unit of $l$, equations (2) and (1) determine a unique output level $x$, and profits are then determined by (3).

A unit of the labor input $l$ involves the performance of many tasks. Following Grossman \& Rossi-Hansberg (2008) we assume a continuum of tasks, indexed by $i \in[0,1]$. Without loss of generality, we assume that for a unitlevel of $l$ the same amount of labor is required on each of these tasks. Units are scaled in such a way that the entire measure of tasks required per unit of $l$ is normalized to one. Thus, the amount of labor needed for tasks located in the sub-interval $[o, \bar{\imath}]$ in order to secure a level $l$ of the labor input is given by $l \int_{0}^{\bar{\imath}} \mathrm{d} i$. Notice that, the elasticity of substitution between different tasks for a given level of $l$ is zero.

We make no distinction between intra-firm performance or outsourcing of tasks to independent suppliers. However, firms decide on where to perform tasks, based on cost advantage. As in Grossman \& Rossi-Hansberg (2008), we assume that tasks may be performed abroad where firms face perfectly elastic supply of labor at a wage rate $w^{*}$. Suppose a firm wants to secure an input level $l$ and it wants to perform the necessary tasks within the subrange $i \in[0, \bar{\imath}]$ abroad. Then the cost of these offshore activities are equal to $w^{*} l \int_{0}^{\bar{\imath}} \beta t(i) \mathrm{d} i$. The term $\beta t(i)$ denotes the extra cost caused by offshore performance of task $i$, over and above the amount of labor needed if the task is performed domestically. This is the familiar notion of "iceberg cost". ${ }^{6}$ The function $t(i)$ depicts the variation of this cost across tasks, while $\beta$ measures the overall costliness of offshoring. For obvious reasons, we assume $\beta \geq 1$

\footnotetext{
${ }^{6}$ There are several interpretations of $\beta t(i)$. Blinder (2006, 2007, 2009) has pointed out that the costs for offshoring a task depend on whether the performance of the task requires personal contact to the customer or not. Levy and Murnane (2004) divided tasks into those that can be described by the use of rule-based logic and those where this is impossible. While for the former tasks a remote performance bears only a modest risk of miscommunication the offshore performance of the latter tasks entails substantial communication costs. Finally, Leamer and Storper (2001) emphasized the difference between tasks that require "codifiable" information and those that require "tacit" information. While the former type of information can be transferred easily with the help of some kind of symbol system, the latter type of information require personal contact. Note also that it is easy to imagine a scenario where the costs of transportation differ across tasks.
} 
and $t(0)=1$. Moreover, without loss of generality, we may rank tasks such that $t^{\prime}(i)>0 .^{7}$

We assume that the domestic labor market is characterized by search frictions. Firms have to post vacancies in order to find suitable workers, and there is a constant cost per vacancy equal to $\kappa$, measured in terms of the final good. The rate at which a vacancy is turned into a successful match is denoted by $q(\theta)$, where $\theta$ denotes the labor market tightness. Denoting the take-away wage per worker by $w$, the cost per unit-level of a task, if performed domestically, is equal to $w+\kappa / q(\theta)$. We shall turn to the determination of $w$ as well as the matching rate $q(\theta)$ below. Moving any task offshore, the firm thus saves on both, domestic factor costs $w$ and hiring costs $\kappa / q(\theta)$. The cost-savings are the same across all tasks. Cost-minimization requires that these savings be offset, at the margin, by the cost of performing a task abroad. Given our ranking of tasks, it is straightforward to determine a marginal task $I$ which separates tasks $i<I$ performed offshore from tasks $i>I$ that are performed drawing on the domestic labor market. The marginal task satisfies

$$
w+\frac{\kappa}{q(\theta)}=\beta t(I) w^{*}
$$

We thus assume that there are no hiring costs for offshoring. Moreover, we assume that $w+\kappa / q(\theta)>\beta t(0) w^{*}$ in order to arrive at a non-trivial offshoring equilibrium with $I>0$. Notice that this does not require $w^{*}<w .{ }^{8}$ The foreign cost advantage derives from a lower wage, as well as the absence of hiring cost. The extensive margin of offshoring $I$ decreases with $\beta$, the overall costliness of offshoring.

If a firm posts $v$ vacancies, it will end up paying $w q(\theta) v$ in terms of wage costs, plus hiring costs $\kappa v$. Given $I$, the profit-maximizing domestic employment $l$ satisfies

$$
\max _{l}\left\{F(l)-\left[w+\frac{\kappa}{q(\theta)}\right] l(1-I)-w^{*} l \beta \int_{0}^{I} t(i) \mathrm{d} i\right\} .
$$

Observing the first order condition (4) on $I$, maximum profits may be rewrit-

\footnotetext{
${ }^{7}$ In Kohler (2004), the unit of offshoring is a task that involves both types of primary inputs, with a perfectly analogous definition of offshoring costs. Within the Grossman \& Rossi-Hansberg (2008) framework the results are highly sensitive to the precise definition of a task; see Kohler (2009). Given the purpose of our analysis as motivated in the introduction, the present definition of a task seems like an obvious choice. Grossman \& Rossi-Hansberg (2009) apply the same notion of offshoring costs, focusing on a different driving force behind offshoring, viz. external scale economies on the task level.

${ }^{8}$ These assumptions are meant to reflect, albeit in a stylized way, one of the hallmarks of the present-day world economy, viz. a doubling of the world labor force through the "entry" of China and India, as well as the ex-Soviet bloc countries; see Freeman (2009).
} 
ten as

$$
\begin{aligned}
\pi & =\max _{l}\left\{F(l)-\left[w+\frac{\kappa}{q(\theta)}\right] \Omega(I) l\right\}, \\
\text { whereby } \Omega(I) & =(1-I)+\frac{\int_{0}^{I} t(i) \mathrm{d} i}{t(I)} .
\end{aligned}
$$

The term $\Omega(I)$ is well known from Grossman \& Rossi-Hansberg (2008). It captures in a concise way the entire factor cost savings from offshoring. Obviously, $\Omega(I)=1$ if $I=0$, and from $t^{\prime}(i)>0$ it follows that $\Omega(I)<1$ if $I>0$. Moreover, it can be shown that $\Omega^{\prime}(I)<0$ for all $I \in(0,1] .{ }^{9}$ Notice that the term $\Omega(I)$ makes the entire schedule of offshoring cost $t(i)$ an integral part of the technology. Indeed, it will become evident as we proceed that the precise form of this schedule plays a key role for job creation and job destruction in the process of enhanced offshoring.

We simplify somewhat by assuming a static hiring decision. The first order condition for employment is

$$
F_{l}(l)=\Omega(I)\left[w+\frac{\kappa}{q(\theta)}\right],
$$

where $F_{l}$ denote the marginal productivity of labor. Solving this equations for $l$, we arrive at equations (2), whereby the labor cost $W$ can now be written as

$$
W=\Omega(I)[w+\kappa / q(\theta)] .
$$

The first order condition on domestic labor then emerges as

$$
\left[F_{l}(l)-\Omega(I) w\right] q(\theta)=\Omega(I) \kappa .
$$

The left-hand side gives the expected job rent from posting a vacancy for an additional unit of $l$, taking into account that cost-minimizing offshoring reduces the wage cost below the negotiated wage for domestic workers. This must be equal to the cost of posting such a vacancy, whereby this cost is similarly affected by cost-savings through offshoring. Put differently, the recruiting cost applies not to the entire unit of $l$, but only to the tasks that are performed domestically. Since recruiting cost $\kappa$ is expressed in terms of the final good (with a unitary price), it must be scaled down on an equal footing with the labor cost through the cost savings term $\Omega(I) .{ }^{10}$

\footnotetext{
${ }^{9}$ Appendix A.1 derives all relevant properties of $\Omega(I)$ that are important for the results of this paper.

${ }^{10}$ In a dynamic model, the firm would maximize the present value of periodic profits, whereby posted vacancies of time $t$ determine the rate of change, at time $t$, in employment through the filling rate $q(\theta)$ (to be determined below) and a job separation rate, usually assumed exogenous in this setup. The job separation rate $\lambda$ and the interest rate $r$ raise the steady state "effective" cost of posting vacancies, such that condition (8) is replaced by $F_{l}(l)=\Omega(I)\{w+(r+\lambda)[\kappa / q(\theta)]\}$. The extensive margin of offshoring $I$ is determined through a condition completely analogous to (4), with $\kappa$ again replaced by $(r+\lambda) \kappa$. Since all results of this paper go through for this dynamic version, it is worth simplifying the analysis to the static version.
} 


\subsection{Wage Bargaining}

For simplicity, we assume that each firm is matched with a single worker. ${ }^{11}$ Given the hiring cost, the firm and the worker find themselves in a bargaining situation, once a match has occurred. We follow the standard approach in assuming a Nash bargaining solution for the wage rate $w$. At this stage, we want to simplify as much as possible, hence we assume a zero outside option for the worker. ${ }^{12}$ Denoting the worker's bargaining power by $\gamma$, Nash bargaining implies a wage rate $w$ that satisfies

$$
\max _{w}\left\{(w)^{\gamma}\left[F_{l}(l)-\Omega(I) w\right]^{1-\gamma}\right\}
$$

whereby $l$ satisfies (8). Notice that the overall surplus from filling a job is equal to $F_{l}(l)$, whereas $F_{l}(l)-\Omega(I) w$ is the firm's job rent, given costsavings $\Omega(I)$ from offshoring tasks $i \in[0, I]$. The first order bargaining condition reads as $\gamma\left[F_{l}(l)-\Omega(I) w\right]=(1-\gamma) \Omega(I) w$. Observing the firstorder condition on $l$ in (8), we obtain

$$
w=\frac{\gamma}{1-\gamma} \frac{\kappa}{q(\theta)} .
$$

It is interesting to note that the same bargaining condition would obtain, if Nash-Bargaining took place in an environment without offshoring, which may appear surprising. But it reflects the simple point mentioned before that offshoring saves on both, the wage cost from employment as well as the hiring cost.

\subsection{Domestic Employment}

We stipulate a simplified version of the standard matching model by Pissarides (2000), in order to determine employment. Given a labor force with mass 1 , the rate at which workers find jobs, denoted by $e$, is determined by the amount of vacancies $v$ according to a matching function $M(1, v)$, which is assumed to be homogeneous of degree 1. Notice that $e=M(1, v)$ and the usual measure of labor market tightness is $\theta \equiv v .^{13}$ The link between vacancies and the entire employment is given by

$$
\theta q(\theta)=(1-I) l
$$

\footnotetext{
${ }^{11}$ This assumption is not entirely innocuous. Given the assumption of a unitary mass of labor, it implies a certain corresponding mass of firms.

${ }^{12}$ It would be easy to introduce an unemployment benefit. However, as we do not want to model government policy in this paper, we simplify by setting the benefit equal to zero.

${ }^{13}$ Labor market tightness is usually defined as the ratio between the number of vacancies and the number of unemployed. In this simplified static version of the matching model, since the entire labor force needs to be matched, the initial number of unemployed is equal to the entire labor force.
} 
The rate at which vacancies are filled is given by $q(\theta):=M / \theta=M(1 / \theta, 1)$. In turn, employment is given by

$$
e=e(\theta):=\theta q(\theta) .
$$

Note that $q^{\prime}(\theta)=-M_{U}^{\prime} / \theta^{2}<0$, where $M_{U}^{\prime}$ is the partial derivative of the matching function with respect to the number of unemployed searching for a match. Any increase in the number of vacancies raises labor market tightness, thus reducing the rate at which vacancies are filled. At the same time, it raises employment, $e^{\prime}(\theta)>0 .{ }^{14}$ Note that this setup implies less than full employment, unless the wage falls all the way down to zero, which is equivalent to a dynamic case where, due to full employment, the outside option in wage bargaining is equal to the ongoing wage.

Following Keuschnigg \& Ribi (2009), we introduce an elasticity $\eta:=$ $-\theta q^{\prime}(\theta) / q(\theta)>0$. Using a caret to denote relative changes, we then have

$$
\hat{e}=(1-\eta) \hat{\theta}
$$

Note that domestic employment evolves at two adjustment margins. ${ }^{15}$ At the extensive margin, firms decide about the fraction of tasks $1-I$ they finally want to perform drawing on domestic labor. The intensive margin describes how much labor $l$ is used in overall production. Other things equal, any increase in the overall employment of labor also increases the number of jobs for domestic workers. As we shall see below, offshoring affects the two margins differently, hence the domestic employment effect depends on the relative strength of the adjustments at the two margins.

\subsection{International Trade}

For the sake of simplicity, we do not explicitly model the foreign economy on an equal footing. As we have mentioned at the outset, we assume a given foreign wage rate $w^{*}$, assuming - a priori - that $w^{*}<[w+\kappa / q(\theta)] /[\beta t(0)]$. The domestic economy thus imports tasks, and exports final goods $x$. Total household income is then equal to

$$
Y=w(1-I) l+(1-\delta) x .
$$

The final term is profit income; see (3). Net imports of the final good $x$ are equal to $Y-\{x-[\kappa / q(\theta)](1-I) l\}$, both in value and quantity terms. Note that imports of the final good $x$ is demand minus output of good $x$ net of the

\footnotetext{
${ }^{14}$ This follows from linear homogeneity of $M$, which implies that $e(\theta)=M(1, v)=$ $M(1, \theta)$, and hence $e^{\prime}(\theta)>0$, with $\hat{e} / \hat{\theta}=1-\eta>0$. This implies that $0<\eta<1$.

${ }^{15}$ We make a distinction between domestic employment of labor and employment of domestic labor, because offshoring allows domestic firms to effectively "employ" foreign labor.
} 
resource use involved in hiring of domestic labor. In turn, imports of tasks are equal to

$$
w^{*} l \beta \int_{0}^{I} t(i) \mathrm{d} i=\left[w+\frac{\kappa}{q(\theta)}\right][\Omega(I)-(1-I)] l
$$

This follows from (5) and (4). The aggregate value of net imports is equal to

$$
\begin{aligned}
B= & Y-x+[\kappa / q(\theta)](1-I) l \\
& +\left[w+\frac{\kappa}{q(\theta)}\right][\Omega(I)-(1-I)] l
\end{aligned}
$$

Recognizing that profits $(1-\delta) x$ are equal to $x-W l$, we may write

$$
\begin{aligned}
Y & =w(1-I) l+x-W l, \\
& =w(1-I) l+x-\Omega(I)[w+\kappa / q(\theta)] l
\end{aligned}
$$

This implies that $B=0$. As expected, if all equilibrium conditions are satisfied, trade is balanced.

\section{Comparative Statics of Globalization}

Our model determines five endogenous variables. These are the extensive margin of offshoring $I$, the input level $l$, and the domestic wage rate $w$ as well as domestic employment $e$ (with a rate of unemployment equal to $1-e$ ), and the labor market tightness $\theta$. The corresponding equilibrium conditions are the cost-minimization condition for offshoring (4), the labor demand equation (8), the bargaining condition (12), and the two conditions relating production to labor market tightness (13) and employment (14). Note that in all of these equations $q(\theta)=M(\theta)$. We now explore the comparative static properties of this equilibrium with respect to the general costliness of offshoring $\beta$. Unless indicated otherwise, we use the hat notation to denote relative changes. In the following, we mainly focus on employment of domestic labor.

Differentiating the first order condition (8) on input $l$ yields

$$
\hat{l}=-\frac{1}{1-\delta} \hat{W}
$$

In what follows, we shall use $\Delta:=1 /(1-\delta)$ for the elasticity of labor demand $l$. Differentiating the first order condition on offshoring (4), we obtain

$$
\eta \hat{\theta}=\hat{\beta}+\zeta(I) \hat{I}
$$

On the right-hand side of this equation, we define $\zeta(I)>0$ as the elasticity of the offshoring-cost-schedule $t(i)$, evaluated at $i=I$. Less costly offshoring, $\hat{\beta}<0$, implies adjustment through an extension of offshoring into more costly 
types of tasks, $\hat{I}>0$, or a lower cost of performing such tasks which may come about through a lower negotiated take-away wage $w$, as well as a lower labor market tightness $\theta$ (and thus easier recruiting). On the left-hand side of equation (22), wage adjustment and labor market tightness are brought together through the bargaining condition (12) which requires that

$$
\hat{w}=-\hat{q}(\theta)=\eta \hat{\theta} .
$$

Returning to the labor demand function (21) and remembering the definition of $W$ in (9), which - together with the offshoring arbitrage condition (22) - implies $\hat{W}=\eta \hat{\theta}+\xi(I) \hat{I}$, we arrive at

$$
\hat{l}=-\Delta[\hat{\beta}+[\xi(I)+\zeta(I)] \hat{I}]
$$

In this equation, we have defined $\xi(I)<0$ as the elasticity of the cost-savings factor $\Omega(I)$. In appendix A1, we show that $\xi(I)+\zeta(I)=\zeta(I)(1-I) / \Omega(I)$. Hence, for interior offshoring equilibria, $I<1$ and $I>0$, we have $\xi(I)+$ $\zeta(I)>0$. Employment of domestic labor $e=(1-I) l$ then adjusts according to

$$
\hat{e}=-\frac{I}{1-I} \hat{I}-\Delta[\hat{\beta}+[\xi(I)+\zeta(I)] \hat{I}]
$$

The first term on the right-hand side of this equation represents what we call the extensive margin of labor demand which reflects job losses or gains through more or less tasks being performed offshore. The second term reflects the intensive margin, following from adjustment of overall labor input in line with changes in labor cost. Note that (25) incorporates a cost-minimizing adjustment of $I$. This equation also highlights the ambiguity which is at the core of this paper: An increase in the extensive margin of offshoring caused by $\hat{\beta}<0$ leads to higher cost-savings from offshoring and, thus, to lower labor costs causing an expansion of labor in production. This is the employment side of what Grossman \& Rossi-Hansberg (2008) call the productivity effect of offshoring. At the same time, however, the very increase in $I$ that is at the heart of this effect also implies a direct loss of jobs since additional tasks are moving offshore. We thus have two opposing forces, with an ambiguous net effect on domestic jobs.

However, we need not stop here, since we know how $\hat{I}$ and $\hat{\beta}$ are related to one another from the arbitrage condition of offshoring (22). But the change in the domestic labor market tightness on the left-hand side of (22) also implies a change in domestic employment. To take account of this interdependency, we express $\hat{I}$ as a function of $\hat{e}$, using (15)

$$
\hat{I}=\frac{\tau \hat{e}-\hat{\beta}}{\zeta(I)},
$$

where we define $\tau:=\eta /(1-\eta)$. Remember that the conventional specification of the matching function implies $1-\eta>0$; see above. 
Putting all pieces together, we now arrive at our core equation

$$
[1+\lambda(I) \tau] \hat{e}=\psi(I) \hat{\beta} .
$$

In this equation we have defined $\lambda(I)$ and $\psi(I)$, respectively, as follows

$$
\begin{aligned}
\lambda(I) & :=\frac{I}{(1-I) \zeta(I)}+\Delta \frac{\xi(I)+\zeta(I)}{\zeta(I)}>0, \\
\psi(I) & :=\frac{I}{(1-I) \zeta(I)}+\Delta \frac{\xi(I)}{\zeta(I)} .
\end{aligned}
$$

In the appendix we show that $[\xi(I)+\zeta(I)] / \zeta(I) \equiv(1-I) / \Omega(I)>0$, hence $\xi(I) / \zeta(I) \equiv(1-I) / \Omega(I)-1<0$. All other endogenous variables follow in a straightforward way from the relevant equations above. In particular, labor market tightness $\theta$ and the domestic wage rate $w$ are positively tied to employment $e$ through (15) and the wage bargaining condition in (23). The term $1+\lambda(I) \tau>0$ reflects a mitigation effect reflecting wage adjustment on the domestic labor market. Moreover, since less costly offshoring, $\hat{\beta}<0$, enhances employment at the intensive margin $l$, we observe a rise in output $x$ and an increase in profits $\pi=(1-\delta) x$. If one assumes that such profits accrue to capital owners, as we do in this paper, capitalists are always on the winning side of offshoring. In contrast, the effect on domestic labor is ambiguous. In the next section we take a closer look at this ambiguity.

\section{Offshoring and Net Job Creation}

Blinder (2009) argues that offshoring will likely gain impetus from further enhancement of IT and become a "big deal". Moreover, in his view "offshoring per se will lead to far more job destruction than job creation in the United States". However, he states that this is a mere belief, subject to the verdict of time. Equation (27) offers a theoretical perspective on what may happen in countries like the US. It is a formal expression that highlights the net effect of job destruction at the extensive margin of offshoring and job creation at the intensive margin, due to the productivity effect. In this section we state two theoretical propositions. In the next section we turn to some illustrative simulations.

A first noteworthy result relates to the role of labor market institutions for the employment effect of enhanced trade in tasks.

Proposition I: i) In qualitative terms the employment effect of enhanced trade in tasks, $\hat{I}>0$ caused by $\hat{\beta}<0$, does not depend on domestic labor market institutions related to matching and wage bargaining. ii) In quantitative terms, the effect is dampened by a high value of the elasticity of matching with respect to labor market tightness. iii) The wage bargaining condition as such is unaffected by trade in tasks, but the wage is indirectly affected through labor market tightness. 
Part i) of this statement is directly evident from equation (27) and the definitions of $\lambda(I)$ and $\psi(I)$. It means that the direction of employment adjustment is entirely a matter of technology. There are two key elements of this model that capture labor market institutions. The first is the matching function $M(1, v)$, and the second is the relative bargaining power of workers and firms, respectively. Part ii) follows from $\tau:=\eta /(1-\eta)$ in the term $1+\lambda(I) \tau$, where $\eta$ is the matching elasticity mentioned in the proposition. Other things equal, a higher $\eta$ implies a lower absolute value of $\hat{e}=[1+\lambda(I) \tau]^{-1} \psi(I) \hat{\beta}$, for any given value of $\hat{\beta}$. The reason for this mitigation effect is the dampening role of wage adjustment to the labor demand shock from trade in tasks. The matching elasticity determines how a shock gets transmitted into a change in employment on the one hand, and wage adjustment on the other; see equation (23).

Part iii) is directly evident from equation (12). This result may seem a bit surprising, as we have assumed frictionless hiring in offshoring. Contrary to speculative arguments often brought up, the possibility to perform tasks through cheap offshore labor does not play a direct role in wage bargaining. The intuition is that at the stage of wage bargaining the possibility of moving tasks offshore does not constitute any valuable outside option for the firm, because it is already at the cost-minimizing extensive margin $I$ of offshoring. Hiring a worker must generate a job rent for the firm that equals the cost of recruiting, whereby both, the job rent and the recruiting cost are appropriately adjusted for the savings effect from offshoring; see (10).

Although the relative bargaining power of the worker thus plays no direct role in the wage and employment effects of offshoring, it does of course determine rent sharing between firms and workers. ${ }^{16}$ Specifically, the relative share of the job surplus going to the firm and the worker, respectively, does change upon $\hat{\beta}<0$. But this comes about, not because offshoring alters wage bargaining as such, but because it affects the equilibrium labor market tightness $\theta$.

A closer examination of $\psi(I)$ in equation (27) allows us to trace out the evolution of net job creation for domestic labor along the entire Blinderian way of offshoring becoming a "big deal", i.e., as successive reductions in $\beta$ lead to ever larger values of $I$. It is instructive to start out at the zerooffshoring margin where (4) is satisfied with $I=0$. In this case, if $\hat{\beta}<0$ leads to incipient offshoring, there is zero job creation. Since there are no inframarginal tasks that could benefit from less costly offshoring, there is no cost-savings effect that could lead to expansion of $l$. Formally, in $\psi(I)$ we have $\xi(I) / \zeta(I) \equiv(1-I) / \Omega(I)-1$ equal to zero if $I=0$. Adjustment is entirely dominated by job destruction from a loss of tasks to for-

\footnotetext{
${ }^{16}$ Of course, the fundamental assumption of an exogenous bargaining power $\gamma$ may be questioned as such. Admittedly, one can certainly imagine ways in which $\beta$ affects $\gamma$ directly.
} 
eign workers. More specifically, we have $\hat{e}=\hat{\beta} /\left[(1+\lambda(0) \tau) t^{\prime}(0)\right]$, where we have replaced $I /[(1-I) \zeta(I)]=t(I) /\left[(1-I) t^{\prime}(I)\right]$, observing additionally that by assumption $t(0)=1$ and $t^{\prime}(I)>0$ for ${ }^{17}$ all $I \in[0,1]$. Note that $\lambda(0)=1 / t^{\prime}(0)+\Delta$.

As we move into interior offshoring equilibria with values of $I>0$, the offsetting intensive margin adjustment of employment $l$ sets in, as further technological improvements cause further reductions of $\beta$. Throughout the entire range of $I \in[0,1)$, we have $I /[(1-I) \zeta(I)]>0$ and $\Delta \xi(I) / \zeta(I)<0$ for the extensive and intensive margins of adjustment, respectively. As indicated by the title of our paper, and contrary to Blinder's conjecture, there is the distinct possibility of positive net job creation resulting from $\hat{\beta}<0$, as $I$ moves through certain subranges of the interval $(0,1)$ where the intensive margin dominates the extensive margin.

While an equilibrium with $I=0$ is obviously relevant, an equilibrium at the other extreme with $I=1$ must be questioned, as it involves zero employment of domestic labor. Indeed, it can be shown that such an equilibrium does not exist. Zero employment of domestic labor would imply zero recruiting, $v=0$ and thus zero labor market tightness, with a "filling rate" $q(\theta) \rightarrow \infty .^{18}$ But according to the wage bargaining condition (12), this implies $w \rightarrow 0$, which is the full-employment-level of wages and therefore contradicts the zero employment as implied by $I=0 .{ }^{19}$ Looking at (4), we also recognize that in such a situation the term $\beta t(1) w^{*}$ would exceed $\kappa / q(\theta)$, with $q(\theta) \rightarrow \infty$, thus leaving room for a positive domestic wage rate with positive employment. Note that this holds true even if $t(1)$ is finite, meaning - in Blinder's terminology - that all tasks are potentially impersonal for realistically low levels of $\beta$. But this seems somewhat odd, hence an equilibrium with $I=0$ would seems questionable also on economic grounds. ${ }^{20}$

But what is it that determines whether non-monotonicity, with positive net job creation over certain subranges of $I$, does arise along the Blinderian "big-deal-journey" of offshoring? As indicated above, the answer lies in the term $\psi(I)$. Non-monotonicity requires that the job loss effect at the extensive margin, $I /[(1-I) \zeta(I)]>0$, eventually becomes dominated by the intensive margin, $\Delta \xi(I) / \zeta(I)$, as $\xi(I) / \zeta(I) \equiv(1-I) / \Omega(I)-1$ takes values below zero, for $I>0$. Obviously, the offshoring cost schedule $t(i)$ plays a key role. We have already emphasized above that this schedule in its entirety becomes an integral part of a domestic firm's technology. It now emerges as the key

\footnotetext{
${ }^{17}$ We shall return to the question of the limiting behavior of $t(i)$ in section 5 where we present a numerical treatment.

${ }^{18}$ In dynamic terms, the duration of a vacancy would be zero. Hiring becomes costless.

${ }^{19}$ Of course, an equilibrium value of $I=1$ is perfectly possible in a multi-sectoral model if labor is mobile across sectors. However, for reasons emphasized in the introduction, we want to focus on the case of intersectoral immobility.

${ }^{20}$ We shall address the limiting behavior of $t(I)$ as $I \rightarrow \infty$ in the next section.
} 
to the possibility of job creation with offshoring of tasks.

Intuitively, the extensive margin is driven by $t^{\prime}(I)$ : A steeper cost-schedule for offshoring additional tasks implies that - other things equal - the arbitrage condition (4) will be restored with a lower measure of additional task-offshoring. At the same time, the intensive margin is driven by the cost-savings reaped from offshoring tasks up to $i=I$, which depends on the entire curvature of $t(i)$ up to $i=I$. In addition, it is driven by the elasticity of labor demand $\Delta$. Sharp insights seem difficult to obtain without venturing a functional form of $t(i)$, which allows us to simulate $\hat{e} / \hat{\beta}$ for the entire span of possible values $I \in[0,1]$. However, we can state the following general proposition.

Proposition II: If we denote the domestic wage cost per unit of labor input $l$ as $d:=[w+\kappa / q(\theta)](1-I)$, and the cost of imported tasks per unit of output as $m:=w^{*} \beta \int_{0}^{I} t(i) \mathrm{d} i$, then, at any interior equilibrium level of offshoring $I \in(0,1)$, the elasticity of employment of domestic labor with respect to the costliness of offshoring is negative, $\hat{e} / \hat{\beta}<0$, if and only if $\Delta \zeta(I)$ is larger than $(d / m+1) I /(1-I)$.

We relegate the proof of this proposition to appendix A2. Note that $\hat{e} / \hat{\beta}<0$ implies a positive net job creation with enhanced offshoring sparked by a reduction in the costliness of trade in tasks. A positive net job creation from enhanced offshoring requires a large enough labor demand elasticity, reinforced by a large elasticity of the cost of offshoring further tasks. In addition, it requires a relatively low ratio of initial domestic labor cost to cost of imported tasks. In the proposition, the term $\Delta \zeta(I)$ captures "local conditions" at the equilibrium extensive margin of offshoring $I$. By way of contrast, the $(d / m+1) I /(1-I)$ depicts the "interval properties" of this margin, meaning the position of $I$ in the interval, as well as the infra-marginal curvature of the $t(i)$-schedule which is reflected in $m$. The numerical analysis below will shed further light on this distinction.

\section{A Numerical Treatment}

In this section, we provide a numerical analysis to substantiate proposition II and to highlight some important implications. Much of the literature on offshoring insinuates that the wage and/or employment effects of offshoring do not systematically vary across stages of production. Our preceding analysis strongly suggests it does. Should Blinder turn out to be right and offshoring becomes a "big deal", as the costs of linking tasks across long distances undergo successive rounds or reductions, then it is likely that the associated employment effects will vary, as industries move from incipient trade in tasks to "high-volume-offshorers". As indicated above, employment may well react in a non-monotonic way. In this section we provide a numerical analysis that 
highlights this potential non-monotonicity.

Toward this end, we must calibrate the schedule $t(i)$. Our approach is not to calibrate it to a specific real world data set. Instead, we want to highlight relevant ways in which industries may differ in their offshoring technologies. It is important to be clear about the meaning of the schedule $t(i)$. Three points need to be observed. First, the schedule does not involve any notion of technological sequencing in which tasks need to be performed. ${ }^{21}$ It represents what Blinder (2009) calls a varying degree to which jobs are of a personal, or impersonal nature. In the present context it is a variation across tasks. To reiterate, $i=0$ indicates the least personal of all tasks, where the additional cost deriving from offshore performance, measured in "iceberg-terms" through $\beta t(i)$, is lowest. In contrast, $i=1$ indicates the least impersonal (or most personal) of all tasks, where the additional cost arising from offshore performance is largest. In the above analysis, we have already normalized $t(0)=1$, and we have treated $\beta \geq 1$ as a cost-shifter that affects all tasks.

Second, the derivative $t^{\prime}(i)$ does not represent the marginal cost of offshoring, which is equal to $\beta t(i) w^{*}$, but is a cost-equivalent measure of the extent to which increasing the margin of offshoring leads into less impersonal types of tasks. It is relatively obvious that the shape of the entire schedule $t(i)$ should vary significantly across industries. Our numerical analysis in this section reveals that this variation may imply vastly different patterns of employment reactions as industries travel along the interval $I \in[0,1){ }^{22}$ Accepting the notion of a continuum of tasks, and the absence of any technological sequencing requirement, assuming $t^{\prime}(i)>0$ implies no restriction whatsoever. Indeed on our level of generality, assuming monotonicity also of the second derivative appears entirely innocuous as well.

The third point relates to the limiting behavior of $t(i)$ as $i \rightarrow 1$. Our analysis suggests that a fundamental distinction must be drawn between industries where this limit is a finite number, henceforth called "type-f industries", and industries where it is equal to infinity. We label such industries "type-i". This distinction has clear economic meaning. Type-f-industries are somewhat akin to what Bhagwati (2006) has called industries with "shallow" or "thin" comparative advantage. ${ }^{23}$ In such industries, a relatively moderate improvement in the technology of linking tasks performed in different locations may lead to a complete dislocation of all tasks. The industry need not disappear altogether, but as regards domestic labor it may degenerate to a mere "offshoring agency". As we have shown above, in the context of our stylized model an f-type industry seems somewhat implausible, since an equi-

\footnotetext{
${ }^{21}$ Sequencing issues are discussed in Harms, Lorz \& Urban (2009).

${ }^{22}$ We acknowledge that a well-behaved equilibrium with $I=1$ does not exist by specifying the relevant interval as an open interval $[0,1)$.

${ }^{23}$ In the present context, comparative "advantage" means viable domestic production.
} 
librium with $I=1$ does not exist, but in a more general context, particularly one with labor mobility between several sectors, it certainly commands some relevance.

By way of contrast, a type-i industry would be one with a somewhat deeper entrenchment of domestic viability, at least as far as offshoring labor is concerned. ${ }^{24}$ As the margin of offshoring rises toward $I=1$, the additional cost deriving from offshore performance of the marginal task approaches infinity. Hence, some tasks will always be retained domestically, even if $\beta$ falls right down to 1 . Given the assumptions made up to this point, and adding twice-differentiability of $t(i)$, type-i industries feature a strictly convex schedule $t(i)$.

From the figure 4 in appendix A1, it is clear that for any given margin $I$, and a given $t(I)$, the cost savings already achieved through offshoring is larger for a convex schedule $t(i)$ than for a concave schedule. Larger costsavings imply a lower value of imported tasks (the term $m$ in proposition II), which in turn implies a lower leverage for further cost-savings to be reaped from further $\hat{\beta}<0$, particularly if the industry is at an "early stage" of offshoring, i.e., at a low value of $I$. All of this is summarized by the "interval property" of proposition II.

Given the "interval property" of any given equilibrium, the labor market effect of a $\beta$-induced further increase in the margin $I$ is determined by the "local conditions". Other things equal, a steeper schedule $t(I)$ implies a muted reaction of $I$ to a given $\hat{\beta}<0$, which in turn limits the job loss at the extensive margin. At the same time, the labor demand effect deriving from further cost-savings is governed by the labor demand elasticity, which is governed by the degree of concavity $\delta$ in the production of the final good. With a large value of $\delta$, even small changes in the unit-cost of $l$ translate into a sizable increase in the entire demand for labor. All of this is captured in a simple way by $\Delta \zeta(I)$ in proposition II.

Armed with this intuition, we can now turn to a numerical view on the aforementioned two types of industries. In the following, we trace out values of $\psi(I)$ throughout the entire interval $I \in[0,1)$ for alternative functional forms representing type-f and type-i industries, respectively. Remember that the sign of $\psi(I)$ determines the sign of the elasticity $\hat{e} / \hat{\beta}$ and, thus, a positive sign implies net job destruction from offshoring, and vice versa.

\footnotetext{
${ }^{24}$ Of course, comparative advantage of the entire industry may still be lost due to other changes unrelated to $\beta$.
} 


\section{$5.1 \quad$ Type-i Industries}

Given what we have said above, the schedule $t(i)$ of type-i industries may be described by a strictly convex function of the form ${ }^{25}$

$$
t(i)=\frac{1}{(1-i)^{\mu}},
$$

where $\mu>0$. It should be noted that the parameter $\mu$ governs both, the steepness and the degree of convexity of the function $t(i)$. A larger value of $\mu$ implies a larger slope at any given $I$, as well as a higher degree of convexity. Given this functional form, the decisive term underlying proposition II emerges as ${ }^{26}$

$$
\psi(I)= \begin{cases}1+\Delta \frac{\ln (1-I)}{1-\ln (1-I)} & \text { if } \mu=1 \\ \frac{1}{\mu}-\Delta \frac{1-(1-I)^{1-\mu}}{1-\mu(1-I)^{1-\mu}} & \text { if } \mu \neq 1 .\end{cases}
$$

Taking limits, we find that $\lim _{I \rightarrow 0} \psi(I)=1 / \mu>0$, while $\lim _{I \rightarrow 1} \psi(I)=$ $(1-\mu) / \mu-\delta /(1-\delta)$ for $\mu \leq 1$, and $\lim _{I \rightarrow 1} \psi(I)=-\delta /(1-\delta) \mu$ for $\mu>1$. Figure 1 depicts the general equilibrium impact of falling offshoring costs on

$$
\mu \cdot \psi(\mathrm{I}) \text { for } \delta=1 / 2
$$

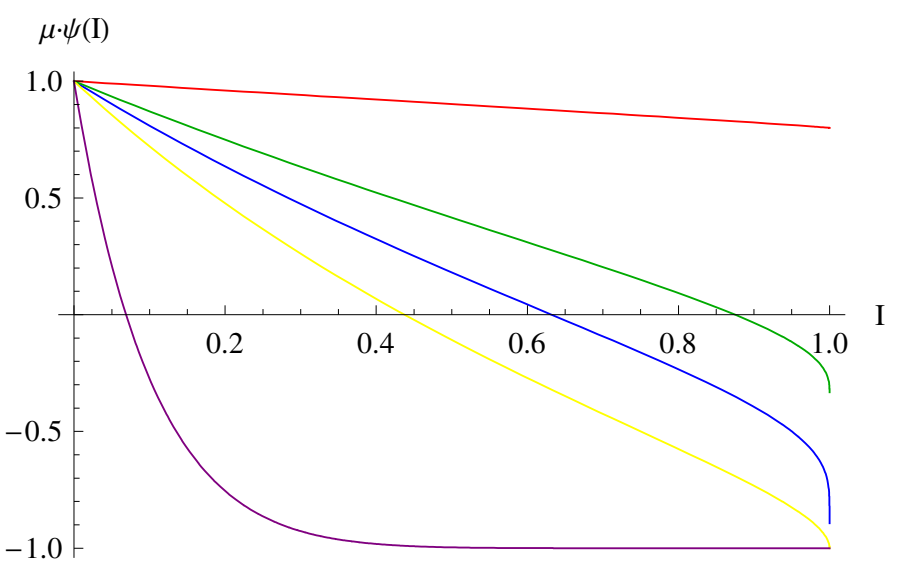

$$
\begin{array}{|l}
-\quad \mu=1 / 10 \\
-\quad \mu=2 / 3 \\
-\quad \mu=1 \\
\\
\mu=3 / 2 \\
-\quad \mu=10
\end{array}
$$

Figure 1: Employment effects of offshoring for type-i industries

employment for $\delta=1 / 2$ and different values of $\mu$. For the sake of illustration, we plot $\mu \psi(I)$, thus anchoring all lines at a common unitary value for $I=$ 0 . Obviously, this type of scaling leaves the horizontal intersection points unaffected. These mark the turning points where the Grossman \& RossiHansberg (2008) productivity effect of offshoring gets turned into a vehicle of net job creation. For low values of $I$, i.e., for for "early" improvements in

\footnotetext{
${ }^{25}$ This case is also briefly considered in Grossman \& Rossi-Hansberg (2008).

${ }^{26}$ See appendix A3 where we derive equation (31) and some useful properties of the function $\psi(I)$.
} 
the technology of linking tasks across countries, offshoring always comes with net job losses. But once the industry reaches a critical level of $I$, measured by the horizontal intersection points in figure 1, further improvements will lead to enhanced offshore performance of tasks, coupled with an increase in employment of domestic labor on account of the "interval property" of proposition II.

However, one must be cautious when interpreting the lines in figure 1 . They do not depict the size of the employment effects as the industry moves from low to high values of $I$. These are governed by the elasticity $\hat{e} / \hat{\beta}$ $=[1+\lambda(I) \tau]^{-1} \psi(I)$. But still, the principal message is simple, clear and important. If the offshoring technology of a type-i industry features a large enough value of $\mu$, then the domestic employment level of this industry features a non-monotonic pattern of adjustment. Initial imports of tasks will be at the expense of domestic jobs, but if further technological improvements take the industry beyond a critical level of offshoring, employment and wages will pick up again. To put it somewhat bluntly, the relationship between domestic jobs and offshoring may be subject to a "curse of small steps": A little bit of offshoring may hurt employment, while a large dose might be a boon. Alas, economies and industries cannot arbitrarily decide about the dose: It is endogenous to $\beta$.

From the above discussion and proposition II, one might expect that the extensive margin eventually starts dominating again, once the industry approaches very high values of $I$. However, for type-i industries the prevalence of "infinitely personal" tasks shields domestic labor from such a scenario. Indeed, it is interesting to note from figure 1 that the employment effect, once turning positive - or, equivalently, $\mu \psi(I)$ turning negative - does not turn negative again, even for very large values of $I .{ }^{27}$ However, whether or not such a pattern emerges depends on the value of $\mu$. Figure 1 reveals that for sufficiently small values, the term $\psi(I)$ converges to a positive number, in which case the adjustment pattern of the industry is monotonic, with job losses throughout the entire Blinderian "big-deal-journey" of offshoring.

\subsection{Type-f Industries}

The same does not hold true for type-f industries, which for the present purpose may be characterized by the following specification of $t(i)$ :

$$
t(i)=1+\phi i^{\epsilon}
$$

with $\phi, \epsilon>0$. Even though the slope of this line is jointly determined by both $\phi$ and $\epsilon$, we may still view $\phi$ as the slope parameter, as it uniquely pins down $t(1)=1+\phi$. In turn, $\epsilon<1(\epsilon>1)$ makes the schedule a concave

\footnotetext{
${ }^{27}$ For reasons pointed out above, in the present model the very far extreme of $I=1$ is devoid of any economic significance, since an equilibrium with $I=1$ does not exist.
} 
(convex) function, while $\epsilon=1$ implies the knife edge case of linearity. It follows from our discussion of the interval property above that the degree of concavity (convexity) is important for the employment effect of offshoring. We therefore provide two separate illustrations of $\psi(I)$, in order to highlight the local conditions and the interval conditions, respectively, for offshoringinduced job creation and job destruction in type-f industries.

The term $\psi(I)$ now emerges as

$$
\psi(I)=\left\{\frac{1}{1-I}-\Delta \frac{\left(1+\frac{\phi}{1+\epsilon} I^{\epsilon}\right) \phi \epsilon I^{\epsilon}}{\left(1+\phi I^{\epsilon}\right)^{2}-\left(1+\phi I^{\epsilon}\right)\left(\frac{\phi \epsilon}{1+\epsilon} I^{\epsilon+1}\right)}\right\}\left(\frac{I^{1-\epsilon}}{\epsilon \phi}+\frac{I}{\epsilon \phi^{2}}\right)
$$

As before, we want to anchor our illustration such that $\psi(0)=1$. It is straightforward to see that for any functional form of $t(i)$ we have $\left[t^{\prime}(I) / t(I)\right] \psi(I)$ approaching a value of 1 as $I$ approaches 0 . Hence we scale our plots accordingly. ${ }^{28}$ Again, caution must be exercised in judging the magnitude of employment effects, but the qualitative adjustment pattern is conveniently captured by figures 2 and 3. Figure 2 highlights variations in the steepness of $t(i)$, while figure 3 highlights different degrees of concavity (convexity). Both figures use $\delta=1 / 2$, as in figure 1 .

A steeper schedule (higher value of $\phi$ ) means - loosely speaking - that for, any value of $I$, the next candidate task for offshoring involves, not just a larger dose of personal elements, but also a larger increase in such elements. For reasons familiar by now, this favors job creation. To understand the role of concavity, one may look at the maximum inframarginal cost savings over the entire range of tasks $I \in[0,1)$. A higher degree of convexity (higher value of $\epsilon$ ) entails a higher potential for inframarginal cost savings. However, there is a second effect. With a more convex (less concave) schedule the relative importance of a single task for the overall cost savings shifts from less personal to more personal tasks.

As before, no adjustment at the intensive margin arises from an equilibrium without offshoring where $I=0$. At the other extreme, for reasons now familiar, job destruction at the extensive margin again dominates when $I \rightarrow 1$. For $I=1$, the second term in the curly bracket of (33) equals a finite number. ${ }^{29}$ With $\lim _{I \rightarrow 1}(1-I)^{-1} \rightarrow \infty$, we thus obtain $\lim _{I \rightarrow 1} \psi(I) \rightarrow \infty$. But it should be remembered that, even though $t(1)$ is finite for type-f industries, within the confines of our model an equilibrium with $I=1$ does not exist.

The irrelevance of $I=1$ notwithstanding, there is a significant difference between type-f and type-i industries. For type-i industries, although the level of employment may follow a non-monotonic pattern of adjustment to successive improvements of the offshoring technology, the employment changes fall

\footnotetext{
${ }^{28}$ This implies that we ignore $I / \zeta(I)=I^{1-\epsilon} / \epsilon \phi+I / \epsilon \phi^{2}>0$ for $I>0$ on the right hand side of equation (33). But this is inconsequential for our qualitative analysis.

${ }^{29}$ To be precise $\Omega^{\prime}(1) / \Omega(1)=(\phi \epsilon) /(1+\phi)$, which is always larger than zero.
} 
$\psi(\mathrm{I}) \cdot \mathrm{t}^{\prime}(\mathrm{I}) / \mathrm{t}(\mathrm{I})$
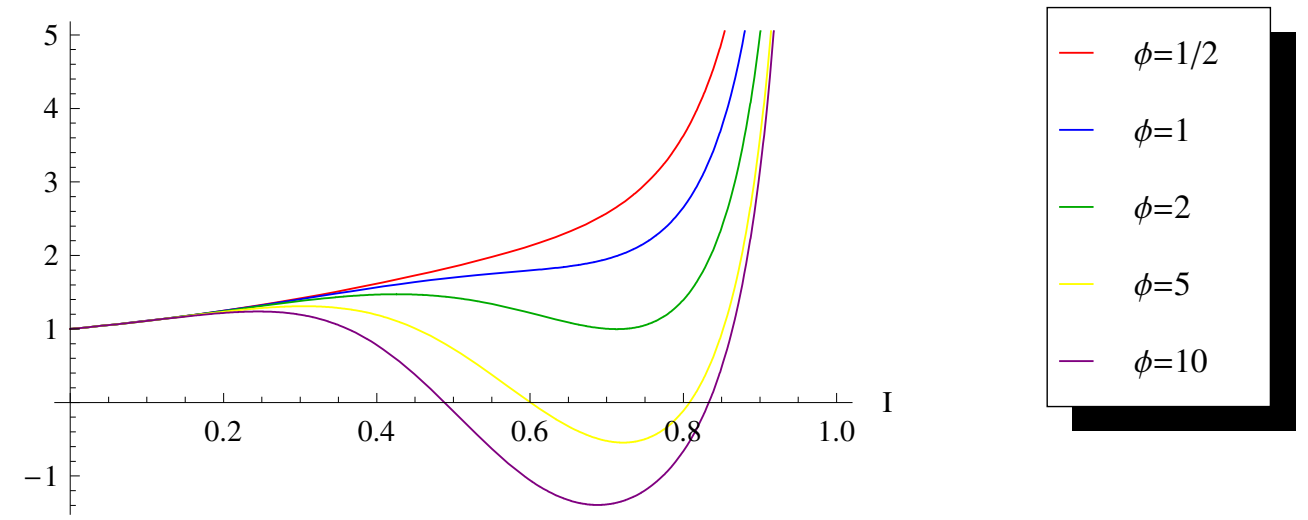

Figure 2: Employment effects of offshoring for type-f industries varying steepness of cost

$\psi(\mathrm{I}) \cdot \mathrm{t}^{\prime}(\mathrm{I}) / \mathrm{t}(\mathrm{I})$ for $\delta=1 / 2$ and $\phi=10$

$\psi(\mathrm{I}) \cdot \mathrm{t}^{\prime}(\mathrm{I}) / \mathrm{t}(\mathrm{I})$

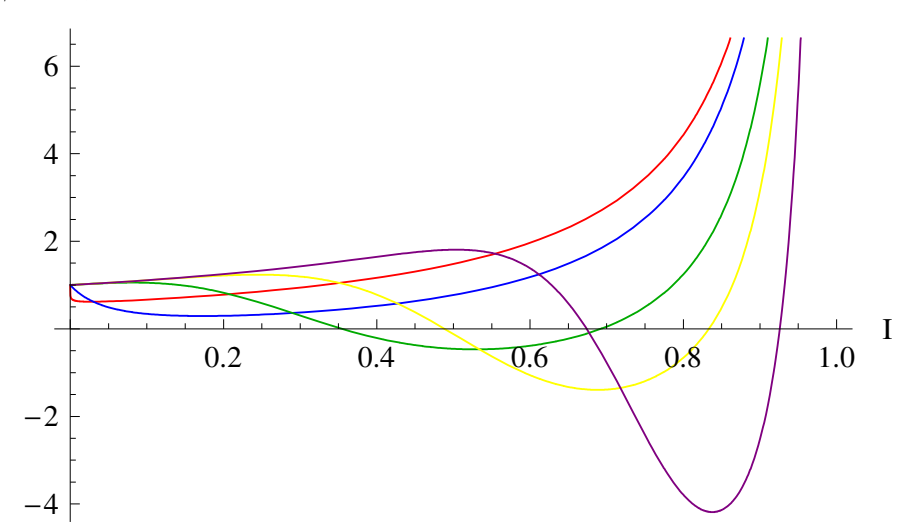

\begin{tabular}{|ll}
\hline- & $\epsilon=1 / 3$ \\
- & $\epsilon=1$ \\
- & $\epsilon=3$ \\
- & $\epsilon=5$ \\
- & $\epsilon=10$ \\
\hline
\end{tabular}

Figure 3: Employment effects of offshoring for type-f industries varying convexity of cost

monotonically as $I$ increases. By way of contrast, given the dominance of the extensive margins both at $I=0$ and as $I \rightarrow 1$, type-f industries necessarily exhibit a non-monotonic pattern of adjustment also in employment levels, as evidenced by figures 2 and 3. However, as with type-i industries, a range of $I$ where offshoring comes with net job creation is no foregone conclusion. As with figure 1, it requires a minimum steepness of the cost schedule also for type-f industries; see figure 2. In other words, in an environment where the tasks affected are almost equally impersonal (or personal), offshoring is unlikely to cause net job creation.

On the other hand, for a given steepness of cost at the margin $I$, net job creation from an enhanced import of tasks requires a minimum degree of convexity, as evidenced from figure 3. But it follows from the interval condi- 
tions of proposition II that any increase in the convexity shifts the relevant range of $I$ where job creation dominates job destruction to the right. Loosely speaking, while convexity may guarantee net job creation from offshoring, it does so at the expense of a longer road where the loss of tasks is first associated with job losses. Witness the line for $\epsilon=10$ in figure 3 rising for low values of $I$. More generally, a convex cost-schedule $t(i)$ means that the "meaty" gains from offshoring only arise toward the upper end of the task range where the level of offshoring cost is already relatively high.

We may summarize this numerical exercise as follows. For both, type-i and type-f industries, if the tasks affected by offshoring are almost equally impersonal in nature, then the employment level will fall monotonically as technological improvements enhance the scope of offshoring. This corresponds to the case highlighted in Keuschnigg \& Ribi (2009). However, if the offshoring cost schedule is rather steep, reflecting a large variation in the costliness of offshore performance across different tasks, and if the cost differentials are also unequally distributed across tasks, then there is a distinct possibility that offshoring comes with net job creation, albeit only after the industry has surpassed a threshold level of offshoring. Generally, this outcome is more likely to arise in type-i industries, where comparative advantage is more deeply entrenched, than in type-f industries with shallow comparative advantage.

For both types of industries, a higher value of $\delta$, implying a less concave production technology, tend to brighten the picture. In terms of figures 1 through 3 , lower values of this parameter would amount to downward shifts of the $\psi(I)$-lines, thus increasing likelihood and relevance of sub-ranges of job-creation ranges within the range of offshorable tasks $[0,1)$.

\section{Conclusion}

In the general public, offshoring is associated, first and foremost, with job losses. This is mirrored by a corresponding rhetoric and attitude of policy makers. Empirical studies have produced mixed results, but it is probably fair to say that overall the evidence does not suggest a strong macroeconomic impact of offshoring on the level of unemployment. Yet, micro-level evidence clearly shows that industrial restructuring often involves a fair dose of offshoring which is associated with domestic job losses.

Existing theoretical models of offshoring shed little light on this issue. With very view exceptions, they rely on general equilibrium trade models that assume full employment. In this paper we have presented a theoretical model that allows us to juxtapose job destruction and job creation as a result of offshoring. Our model envisages a process of "high-resolution globalization", whereby profit maximizing decisions about sourcing of tasks lead to a steady increase in the share of tasks performed offshore, due to an improved technology of linking tasks across distance and country borders. We call this 
the extensive margin of job destruction. At the same time, however, there is an intensive margin of job creation where cost-savings that derive from such technological improvements induce firms to expand their entire production and thus their labor demand. Modeling both in a unified framework of job search and matching, we are able to identify the forces that govern the relative strengths of the two job margins in the adjustment to less costly offshoring. The forces depend on details of the cost schedule that describes the relative ease with which different tasks - lined up in a continuum - may be moved to an offshore low-cost location. This reflects varying degrees to which tasks are personal or impersonal in nature. A key result of the paper is that what matters is not just the slope of this schedule at the relevant extensive margin of offshoring, but also its degree of convexity/concavity within the range of tasks already performed offshore to start with.

A process of steady increase in offshoring, as envisaged by Blinder (2009) and others, involves a systematic variation in the relative importance of job destruction and job creation. We have traced out this variation theoretically, as well as through a numerical analysis. The conclusion is that for certain types of industries, identified by particular characteristics of their offshoring technology, the conditions for net job creation will be met. However, they will typically be met only at relatively late stages of offshoring, where technological improvements dictate offshoring also of tasks that are relatively personal in nature, with less personal tasks already having fallen victim to offshoring due to earlier improvements. We identify something like the "curse of small steps", meaning that a small dose of incipient offshoring is likely to hurt in terms of job losses and wage cuts, whereas further doses may lead to job and wage gains.

However, such non-monotonicity is not a foregone conclusion, but it is a distinct possibility. Whether or not it arises depends on both, the slope and the degree of convexity of the offshoring cost schedule. Loosely speaking, the larger the variation across tasks in the degree to which they are personal or impersonal, the stronger the job creation effect in later stages of offshoring. In a similar vein, the more equally dispersed the differences in the degree of personality across tasks, the more likely a net job gain at later stages of offshoring.

\section{Appendix}

\section{A1 Properties of $\Omega(I)$}

Since offshoring provides a possibility to save on labor cost, one should expect that $\Omega(I)<1$. This inequality can be rewritten as

$$
\int_{0}^{I} t(i) \mathrm{d} i<I t(I)
$$


which holds true for all $I \in(0,1]$ if $t^{\prime}(i)>0$ for all $i \in[0,1]$. Hence, $\Omega(I)<1$ for all $I \in(0,1]$. It is instructive to depict this term graphically.

$\mathrm{t}(\mathrm{i})=1+i^{\epsilon}$ for $\epsilon=1 / 3, \epsilon=1$ and $\epsilon=3$ as well as $\mathrm{t}(\mathrm{i})=(1-\mathrm{i})^{-\mu}$ with $\mu=1 / 10$

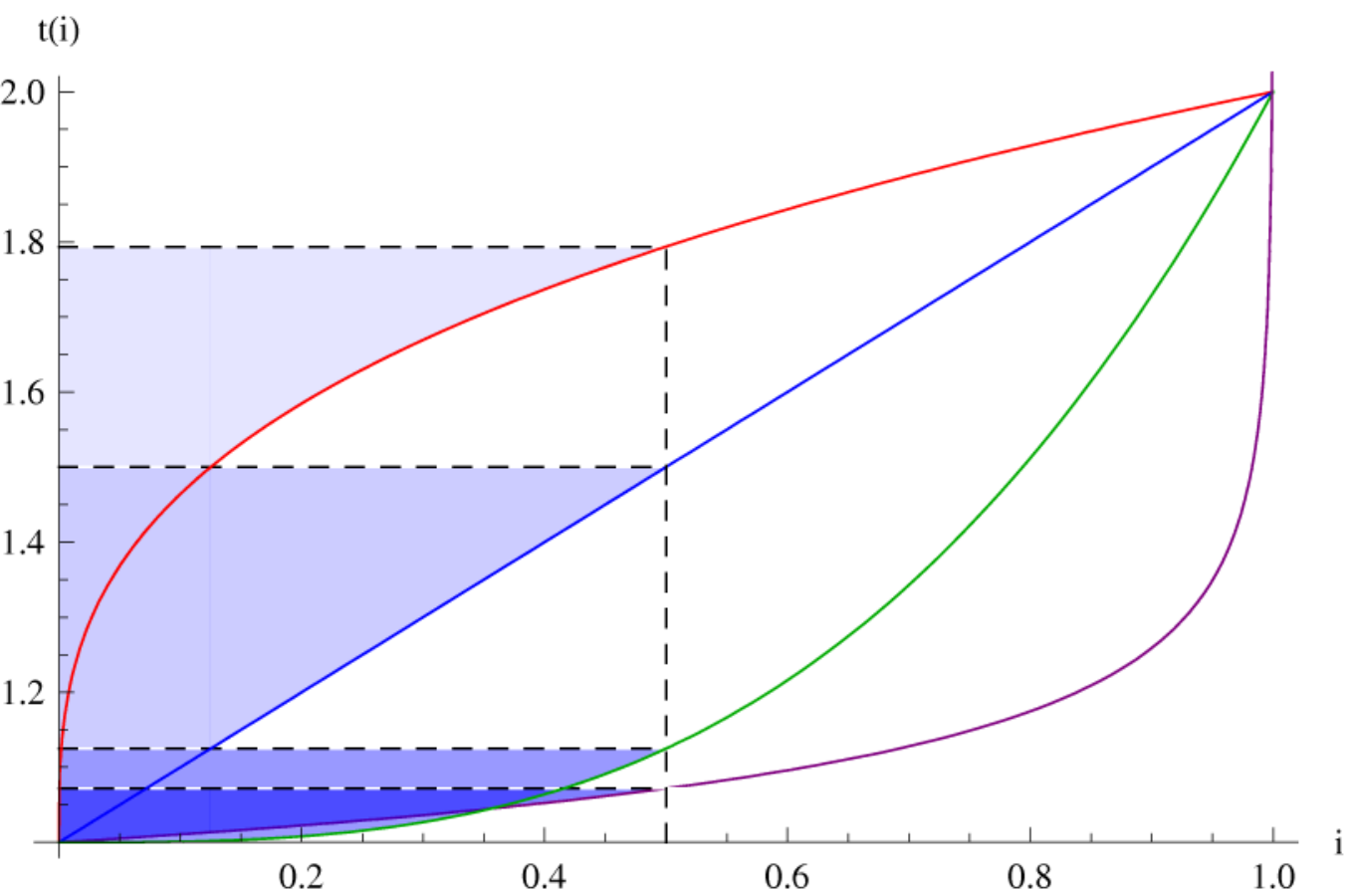

Figure 4: Inframarginal factor cost savings for $f$ - and $i$-type industries

Thus, in figure 4 the shaded areas are measures of the cost-savings from offshoring, i.e., $t(I)[1-\Omega(I)]$, at $I=0.5$ for alternative functional forms of $t(i)$. The diagram nicely highlights the inframarginal nature of $\Omega(I)$.

The first derivative of $\Omega(I)$ with respect to $I$ equals

$$
\frac{\mathrm{d} \Omega(I)}{\mathrm{d} I}=-\frac{\int_{0}^{I} t(i) \mathrm{d} i t^{\prime}(I)}{[t(I)]^{2}} .
$$

Note that $\Omega^{\prime}(I)<0$ for all $I \in(0,1]$ while $\Omega^{\prime}(I)=0$ if $I=0$. Moreover, defining the elasticities $\xi(I):=\Omega^{\prime}(I) I / \Omega(I)$ and $\zeta(I):=t^{\prime}(I) I / t(I)$, we have

$$
\frac{\xi(I)}{\zeta(I)}=\frac{-\int_{0}^{I} t(i) \mathrm{d} i}{t(I) \Omega(I)}<0 .
$$

In addition, we have

$$
\begin{aligned}
\xi(I)+\zeta(I) & =-\frac{\int_{0}^{I} t(i) \mathrm{d} i t^{\prime}(I)}{[t(I)]^{2}} \frac{I}{\Omega(I)}+\frac{t^{\prime}(I) I}{t(I)} \\
& =\left[-\frac{\int_{0}^{I} t(i) \mathrm{d} i}{t(I) \Omega(I)}+1\right] \frac{t^{\prime}(I) I}{t(I)}>0,
\end{aligned}
$$


and

$$
\frac{\xi(I)+\zeta(I)}{\zeta(I)}=\left[\frac{-[\Omega(I)-(1-I)]}{\Omega(I)}+1\right]=\frac{1-I}{\Omega(I)}>0 .
$$

\section{A2 Proof of Proposition II}

Taking equation (27), and observing that $[1+\lambda(I) \tau]>0$, it follows that $\hat{e} / \hat{\beta}<0$, if and only if

$$
\psi(I)=\frac{I}{1-I} \frac{1}{\zeta(I)}+\Delta \frac{\xi(I)}{\zeta(I)}<0
$$

which may be rewritten as

$$
\frac{\Omega(I)}{1-I}+\Delta \Omega^{\prime}(I)<0
$$

Inserting $\Omega^{\prime}(I)$ from the appendix, we obtain

$$
\int_{0}^{I} t(i) \mathrm{d} i\left[\frac{1}{1-I}-\Delta \frac{t^{\prime}(I)}{t(I)}\right]<-t(I)
$$

Multiplying both sides by $\beta w^{*}$, and using (4), we may write

$$
m\left[1-\Delta \frac{t^{\prime}(I)}{t(I)}(1-I)\right]<-\beta w^{*} t(I)(1-I)=-d .
$$

Rearranging terms and multiplying out by -1 , we finally obtain

$$
\Delta \zeta(I)>\left(\frac{d}{m}+1\right) \frac{I}{1-I},
$$

which completes the proof.

\section{A3 Derivation of $\psi(I)$ for $t(i)=(1-i)^{-\mu}$}

Given the offshoring cost schedule $t(i)=(1-i)^{-\mu}$ the aggregated offshoring costs for the range of tasks $I$ can be calculated as

$$
\int_{0}^{I} t(i) \mathrm{d} i= \begin{cases}-\ln (1-I) & \text { if } \mu=1 \\ \frac{1-(1-I)^{1-\mu}}{1-\mu} & \text { if } \mu \neq 1\end{cases}
$$

Inserting these expressions into equation (7) and (A.2) yields

$$
\frac{\Omega^{\prime}(I)}{\Omega(I)}= \begin{cases}\frac{\ln (1-I)}{[1-\ln (1-I)](1-I)} & \text { if } \mu=1 \\ -\frac{\mu-\mu(1-I)^{1-\mu}}{\left[1-\mu(1-I)^{1-\mu}\right](1-I)} & \text { if } \mu \neq 1\end{cases}
$$


Finally the equations above can be combined with $I / \zeta(I)=(1-I) / \mu$ in order to obtain equation (31). The first order derivative of equation (31) with respect to $I$ can be written as

$$
\frac{\partial \psi(I)}{\partial I}= \begin{cases}-\left(1+\frac{\alpha \delta}{1-\delta}\right) \frac{(1-I)^{-1}}{[1-\ln (1-I)]^{2}} & \text { if } \mu=1 \\ -\left(1+\frac{\alpha \delta}{1-\delta}\right) \frac{(1-\mu)^{2}(1-I)^{-\mu}}{\left[1-\mu(1-I)^{1-\mu}\right]^{2}} & \text { if } \mu \neq 1\end{cases}
$$

which is strictly negative for $I \in(0,1]$.

\section{References}

[1] Bhagwati, Jagdish (2006). Globalization and Sweden, Lecture delivered in Stockholm on 27th June, under the auspices of the Confederation of Swedish Enterprise ${ }^{30}$

[2] Bhagwati, Jagdish (2009). "Don’t Cry for Free Trade." In B. Friedman, ed., Offshoring of American Jobs. What Response from U.S. Economic Policy?, Cambridge, Mass.: MIT Press, 1-18.

[3] Bhagwati, Jagdish and Panagariya, Arvind and Srinivasan T.N. (2004). "The Muddles over Outsourcing." Journal of Economic Perspectives, 18(4), 93-114.

[4] Blinder, Alan S. (2005). "Fear of Offshoring." CEPS Working Paper No. 119.

[5] Blinder, Alan S. (2006). "Offshoring: The Next Industrial Revolution?" Foreign Affairs, 85(2), 113-128.

[6] Blinder, Alan S. (2007). "How Many U.S. Jobs Might Be Offshorable?" World Economics, 10(2), 41-78.

[7] Blinder, Alan S. (2009). "Offshoring: Big Deal, or Business as Usual?" In B. Friedman, ed., Offshoring of American Jobs. What Response from U.S. Economic Policy?, Cambridge, Mass.: MIT Press, 19-60.

[8] Bottini, Novella and Ernst, Christoph and Luebker, Malte. (2007). "Offshoring and the Labour Market: What are the Issues?" ILO Economic and Labour Market Paper 2007/11.

[9] Cohen, Daniel. (2009). Three Lecutres on Post-Industrial Society. Cambridge, Mass: MIT Press.

\footnotetext{
${ }^{30}$ www.svensktnaringsliv.se/multimedia/archive/00004/Sweden_and_Globalizat_4601a.pdf.
} 
[10] European Foundation for the Improvement of Living and Working Conditions (2007), Restructuring and Employment in the EU: The Impact of Gobalisation, ERM REPORT 2007, Dublin.

[11] Feenstra, Robert C. (2010). Offshoring in the Global Economy, Microeconomic Structure and Macroeconomic Implications. Cambridge, Mass: MIT Press.

[12] Felbermayr, Gabriel and Prat, Julien and Schmerer, Hans-Jörg (2009). "Trade and Unemployment: What Do the Data Say?" IZA Discussion Paper No. 4184.

[13] Freeman, Richard (2009). "Comment" in B. Friedman, ed., Offshoring of American Jobs. What Response from U.S. Economic Policy?, Cambridge, Mass.: MIT Press, 61-71.

[14] Grossman, Gene M. and Rossi-Hansberg, Esteban (2006). "The Rise of Offshoring: It's Not Wine for Cloth Anymore." The New Economic Geography: Effects and Policy Implications, Federal Reserve Bank of Kansas City, Jackson Hole Symposium, 2006.

[15] Grossman, Gene M. and Rossi-Hansberg, Esteban (2008). "Trading Tasks: A Simple Theory of Offshoring." American Economic Review, 98(5), 1978-1997.

[16] Grossman, Gene M. and Rossi-Hansberg, Esteban (2009). "Task Trade between Similar Countries." Mimeo, Princeton University, first version appearing as NBER Working Paper No. 14554.

[17] Harms, Philipp, Lorz, Oliver and Urban, Dieter (2009). "Offshoring Along the Production Chain." CESifo Working Paper No. 2564.

[18] Keuschnigg, Christian and Ribi, Evelyn (2009). "Outsourcing, Unemployment and Welfare Policy." Journal of International Economics, 78(1), 168-176.

[19] Kohler, Wilhelm (2004). "International Outsourcing and Factor Prices with Multistage Production." Economic Journal, 114(494), 166-185.

[20] Kohler, Wilhelm (2009). "Offshoring: Why Do Stories Differ?" CESifo Working Paper 2232, published in G. Tondl (ed.), The EU and Emerging Markets. Vienna, Springer-Verlag, 2009, pp. 17-49.

[21] Krugman, Paul R. (2008). "Trade and Wages, Reconsidered." Brookings Paper on Economic Activity 2008(1), 103-137.

[22] Lawrence, Robert (2009). "Comment" in B. Friedman, ed., Offshoring of American Jobs. What Response from U.S. Economic Policy?, Cambridge, Mass.: MIT Press, 91-100. 
[23] Leamer, Edward E. and Storper, Michael (2001). "The Economic Geography of the Internet Age." Journal of International Business Studies, 32(4), 641-665.

[24] Levy, Frank and Murnane, Richard (2004). The New Division of Labor, Princeton, N.J.: Princeton University Press.

[25] National Academy of Public Administration (2006), Off-Shoring: How Big Is It?, Washington: DC.

[26] OECD (2007). Offshoring and Employment: Trends and Impacts, OECD, Paris.

[27] Pissarides, Christopher A. (2000). Equilibrium Unemployment Theory, 2nd ed., Cambridge, Mass.: MIT Press. 


\section{CESifo Working Paper Series}

for full list see www.cesifo-group.org/wp

(address: Poschingerstr. 5, 81679 Munich, Germany, office@cesifo.de)

2953 Roland Strausz, The Political Economy of Regulatory Risk, February 2010

2954 Sanjay Jain, Sumon Majumdar and Sharun W. Mukand, Workers without Borders?

Culture, Migration and the Political Limits to Globalization, February 2010

2955 Andreas Irmen, Steady-State Growth and the Elasticity of Substitution, February 2010

2956 Bengt-Arne Wickström, The Optimal Babel - An Economic Framework for the Analysis of Dynamic Language Rights, February 2010

2957 Stefan Bauernschuster and Helmut Rainer, From Politics to the Family: How Sex-Role Attitudes Keep on Diverging in Reunified Germany, February 2010

2958 Patricia Funk and Christina Gathmann, How do Electoral Systems Affect Fiscal Policy? Evidence from State and Local Governments, 1890 to 2005, February 2010

2959 Betsey Stevenson, Beyond the Classroom: Using Title IX to Measure the Return to High School Sports, February 2010

2960 R. Quentin Grafton, Tom Kompas and Ngo Van Long, Biofuels Subsidies and the Green Paradox, February 2010

2961 Oliver Falck, Stephan Heblich, Alfred Lameli and Jens Suedekum, Dialects, Cultural Identity, and Economic Exchange, February 2010

2962 Bård Harstad, The Dynamics of Climate Agreements, February 2010

2963 Frederick van der Ploeg and Cees Withagen, Is There Really a Green Paradox?, February 2010

2964 Ingo Vogelsang, Incentive Regulation, Investments and Technological Change, February 2010

2965 Jan C. van Ours and Lenny Stoeldraijer, Age, Wage and Productivity, February 2010

2966 Michael Hoel, Climate Change and Carbon Tax Expectations, February 2010

2967 Tommaso Nannicini and Roberto Ricciuti, Autocratic Transitions and Growth, February 2010

2968 Sebastian Brauer and Frank Westermann, A Note on the Time Series Measure of Conservatism, February 2010

2969 Wolfram F. Richter, Efficient Education Policy - A Second-Order Elasticity Rule, February 2010 
2970 Tomer Blumkin, Yoram Margalioth and Efraim Sadka, Taxing Children: The Redistributive Role of Child Benefits - Revisited, February 2010

2971 Chang Woon Nam and Georg Wamser, Application of Regionally Varying Additionality Degrees in the Practice of EU Cohesion Policy, February 2010

2972 Ali Bayar, Frédéric Dramais, Cristina Mohora, Masudi Opese and Bram Smeets, Modeling Russia for Climate Change Issues, February 2010

2973 Magnus Söderberg, Informal Benchmarks as a Source of Regulatory Threat in Unregulated Utility Sectors, March 2010

2974 Piotr Wdowiński and Marta Malecka, Asymmetry in Volatility: A Comparison of Developed and Transition Stock Markets, March 2010

2975 Frans van Winden, Michal Krawczyk and Astrid Hopfensitz, Investment, Resolution of Risk, and the Role of Affect, March 2010

2976 Hyun-Ju Koh and Nadine Riedel, Do Governments Tax Agglomeration Rents?, March 2010

2977 Johann K. Brunner and Susanne Pech, Optimum Taxation of Bequests in a Model with Initial Wealth, March 2010

2978 Guglielmo Maria Caporale and Nicola Spagnolo, Stock Market Integration between three CEECs, Russia and the UK, March 2010

2979 Florian Englmaier, Ales Filipi and Ravi Singh, Incentives, Reputation and the Allocation of Authority, March 2010

2980 Konstantinos Angelopoulos, George Economides and Apostolis Philippopoulos, What is the Best Environmental Policy? Taxes, Permits and Rules under Economic and Environmental Uncertainty, March 2010

2981 Frederick van der Ploeg, Rapacious Resource Depletion, Excessive Investment and Insecure Property Rights, March 2010

2982 Wolfram F. Richter and Christoph Braun, Efficient Subsidization of Human Capital Accumulation with Overlapping Generations and Endogenous Growth, March 2010

2983 Francesco Cinnirella, Marc Piopiunik and Joachim Winter, Why Does Height Matter for Educational Attainment? Evidence from German Pre-Teen Children, March 2010

2984 Bernard Van Praag, Well-being Inequality and Reference Groups - An Agenda for New Research, March 2010

2985 Francesca Barion, Raffaele Miniaci, Paolo M. Panteghini and Maria Laura Parisi, Profit Shifting by Debt Financing in Europe, March 2010 
2986 Alexander Haupt and Magdalena Stadejek, The Choice of Environmental Policy Instruments: Energy Efficiency and Redistribution, March 2010

2987 John Komlos and Marek Brabec, The Trend of BMI Values among US Adults, March 2010

2988 Emanuele Massetti and Lea Nicita, The Optimal Climate Policy Portfolio when Knowledge Spills across Sectors, March 2010

2989 Helmut Rainer and Thomas Siedler, Family Location and Caregiving Patterns from an International Perspective, March 2010

2990 Toru Kikuchi and Ngo Van Long, A Simple Model of Service Offshoring with Time Zone Differences, March 2010

2991 Assaf Razin, Efraim Sadka and Benjarong Suwankiri, Migration and the Welfare State: Dynamic Political-Economy Theory, March 2010

2992 Bård Harstad, Buy Coal! Deposit Markets Prevent Carbon Leakage, March 2010

2993 Axel Dreher, Stephan Klasen, James Raymond Vreeland and Eric Werker, The Costs of Favoritism: Is Politically-driven Aid less Effective?, March 2010

2994 Sven Neelsen and Thomas Stratmann, Effects of Prenatal and Early Life Malnutrition: Evidence from the Greek Famine, March 2010

2995 Claude Hillinger and Bernd Süssmuth, The Quantity Theory of Money: An Assessment of its Real Linchpin Prediction, March 2010

2996 Matthew M. Chingos and Martin R. West, Do More Effective Teachers Earn More Outside of the Classroom?, March 2010

2997 Laurence Jacquet and Dirk Van de gaer, A Comparison of Optimal Tax Policies when Compensation or Responsibility Matter, March 2010

2998 Valentina Bosetti, Carlo Carraro, Romain Duval and Massimo Tavoni, What Should we Expect from Innovation? A Model-Based Assessment of the Environmental and Mitigation Cost Implications of Climate-Related R\&D, March 2010

2999 Scott Alan Carson, Nineteenth Century Stature and Family Size: Binding Constraint or Productive Labor Force?, March 2010

3000 Jukka Pirttilä and Ilpo Suoniemi, Public Provision, Commodity Demand and Hours of Work: An Empirical Analysis, March 2010

3001 Bertrand Candelon and Franz C. Palm, Banking and Debt Crises in Europe: The Dangerous Liaisons?, March 2010

3002 Joan Costa-i-Font and Marin Gemmill-Toyama, Does Cost Sharing really Reduce Inappropriate Prescriptions?, March 2010 
3003 Scott Barrett, Climate Treaties and Backstop Technologies, March 2010

3004 Hans Jarle Kind, Tore Nilssen and Lars Sørgard, Price Coordination in Two-Sided Markets: Competition in the TV Industry, March 2010

3005 Jay Pil Choi and Heiko Gerlach, Global Cartels, Leniency Programs and International Antitrust Cooperation, March 2010

3006 Aneta Hryckiewicz and Oskar Kowalewski, Why do Foreign Banks Withdraw from other Countries? A Panel Data Analysis, March 2010

3007 Eric A. Hanushek and Ludger Woessmann, Sample Selectivity and the Validity of International Student Achievement Tests in Economic Research, March 2010

3008 Dennis Novy, International Trade and Monopolistic Competition without CES: Estimating Translog Gravity, April 2010

3009 Yin-Wong Cheung, Guonan Ma and Robert N. McCauley, Renminbising China's Foreign Assets, April 2010

3010 Michel Beine and Sara Salomone, Migration and Networks: Does Education Matter more than Gender?, April 2010

3011 Friedrich Schneider, Tilman Brück and Daniel Meierrieks, The Economics of Terrorism and Counter-Terrorism: A Survey (Part I), April 2010

3012 Friedrich Schneider, Tilman Brück and Daniel Meierrieks, The Economics of Terrorism and Counter-Terrorism: A Survey (Part II), April 2010

3013 Frederick van der Ploeg and Steven Poelhekke, The Pungent Smell of "Red Herrings": Subsoil Assets, Rents, Volatility and the Resource Curse, April 2010

3014 Vjollca Sadiraj, Jan Tuinstra and Frans van Winden, Identification of Voters with Interest Groups Improves the Electoral Chances of the Challenger, April 2010

3015 Guglielmo Maria Caporale, Davide Ciferri and Alessandro Girardi, Time-Varying Spot and Futures Oil Price Dynamics, April 2010

3016 Scott Alan Carson, Racial Differences in Body-Mass Indices for Men Imprisoned in $19^{\text {th }}$ Century US Prisons: A Multinomial Approach, April 2010

3017 Alessandro Fedele, Paolo M. Panteghini and Sergio Vergalli, Optimal Investment and Financial Strategies under Tax Rate Uncertainty, April 2010

3018 Laurence Jacquet, Take it or Leave it: Take-up, Optimal Transfer Programs, and Monitoring, April 2010

3019 Wilhelm Kohler and Jens Wrona, Offshoring Tasks, yet Creating Jobs?, April 2010 